\section{(6) OPEN ACCESS}

\title{
Unemployment insurance and deteriorating self-rated health in 23 European countries
}

\author{
Tommy Ferrarini, Kenneth Nelson, Ola Sjöberg
}

\begin{abstract}
- Additional material is published online. To view please visit the journal (http:// dx.doi.org/10.1136/jech-2013203721).
\end{abstract}

Swedish Institute for Social Research, Stockholm University, Stockholm, Sweden

\section{Correspondence to} Professor Kenneth Nelson, Swedish Institute for Social Research, Stockholm University, Stockholm 106 91, Sweden; kennethn@sofi.su.se

Received 5 December 2013 Revised 15 February 2014 Accepted 18 February 2014 Published Online First 10 March 2014

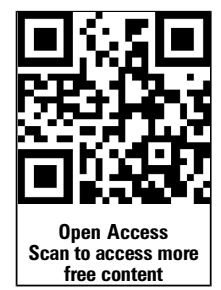

CrossMark

To cite: Ferrarini $\mathrm{T}$, Nelson K, Sjöberg 0. J Epidemiol Community Health 2014;68:657-662.

\begin{abstract}
Background The global financial crisis of 2008 is likely to have repercussions on public health in Europe, not least through escalating mass unemployment, fiscal austerity measures and inadequate social protection systems. The purpose of this study is to analyse the role of unemployment insurance for deteriorating self-rated health in the working age population at the onset of the fiscal crisis in Europe.

Methods Multilevel logistic conditional change models linking institutional-level data on coverage and income replacement in unemployment insurance to individuallevel panel data on self-rated health in 23 European countries at two repeated occasions, 2006 and 2009.

Results Unemployment insurance significantly reduces transitions into self-rated ill-health and, particularly, programme coverage is important in this respect. Unemployment insurance is also of relevance for the socioeconomic gradients of health at individual level, where programme coverage significantly reduces health risks attached to educational attainment.

Conclusions Unemployment insurance mitigated adverse health effects both at individual and countrylevel during the financial crisis. Due to the centrality of programme coverage, reforms to unemployment insurance should focus on extending the number of insured people in the labour force.
\end{abstract}

\section{INTRODUCTION}

The global financial crisis of 2008 is likely to have repercussions on public health in Europe, not least through escalating mass unemployment, fiscal austerity and inadequate social protection systems. ${ }^{1}$ $\mathrm{WHO}^{2}$ recently expressed worries that developments may turn into a health crisis. Due to the socioeconomic gradients of health, we may further expect that health effects of the economic crisis are unequally distributed in society, with citizens in lower socioeconomic positions being particularly exposed. $^{3}$

The purpose of this study is to analyse the role of unemployment insurance for transitions into selfrated ill-health among the working-age population in 23 European countries during the onset of the global financial crisis between 2006 and 2009. Research on social protection and health is typically based on social expenditure data ${ }^{4}$ or on categorisations of countries into welfare state regimes. ${ }^{67}$ These research strategies have provided important insights, but in terms of analysing distinct policy impacts they have analytical shortcomings. The poor validity of social expenditure to account for welfare state structures is well known. ${ }^{8-13}$ Perhaps the most serious problem is that social expenditures are heavily influenced by welfare needs and changes in the gross domestic product (GDP), the most widely used denominator. Welfare state regime classifications suffer from other and less recognised validity problems. In social epidemiology, welfare state regimes are often used as additional country-level variables to measure economic, political and institutional effects on public health. While this approach may show how welfare states function in different economic and political contexts, one drawback is that regime labels often are crude approximations of realities, suitable more as heuristic devices in descriptive analysis than addressing causal questions about policy effects. ${ }^{14}$ To gain a deeper understanding about how social protection contributes to healthier societies, we therefore need stronger focus on programmatic effects.

Empirical investigations in this study are based on an analytical approach where legislated structures of unemployment insurance are at the centre. Appropriate dimensions of unemployment insurance are here systematically conceptualised and measured to facilitate large-scale comparative analyses of links between social protection and health. Specifically, we evaluate the role of unemployment insurance coverage and income replacement for self-rated health.

The health effects of recessions are subject for intense discussion. Macro-level analyses, surprisingly, show that economic downturns have few adverse effects on population health in highincome countries. In the short term, mortality may even decrease during recessions, and increase in economic upturns. ${ }^{15} 16$ Changes in risky behaviours is one proposed explanation for these counter-cyclical fluctuations in population health. ${ }^{17}$ However, macro-level relationships cannot straightforwardly be deduced to circumstances affecting health at individual level, where studies repeatedly demonstrate higher prevalence of ill-health among people in socioeconomically vulnerable positions. ${ }^{18}$ Although poverty and/or low income are important for the socioeconomic distribution of health, surprisingly few studies explicitly analyse the mediating effects of social protection. A recent study on the financial crisis and health in Europe concludes that the most vulnerable people are found in countries having largest public budget cuts and greatest unemployment increases. ${ }^{1}$ Results of this kind call for research on how policy-related factors structure individual health, and here unemployment insurance constitutes a crucial point of departure.

Theoretically, it is reasonable to assume that there are several pathways linking unemployment insurance to self-rated health. First, unemployment insurance reduces volatility of household income by transferring money to the unemployed who can invest resources in health-enhancing goods and 
activities. This consumption effect of increased household income is expected to occur even after more basic material needs have been satisfied, ${ }^{19}$ although with reduced health returns at higher income levels. ${ }^{20} 21$ Second, unemployment insurance plays an important redistributive role, lowering income differences in society, of relevance for the psychosocial foundations of health. ${ }^{22}$ Third, unemployment insurance may have beneficial health effects also for those in employment, not least by reducing feelings of stress and anxiety that may follow periods of increased job insecurity in society as a whole. ${ }^{23}$

Although we may not fully disentangle these pathways, we can formulate two overarching hypotheses. At country level, we expect more extensive unemployment insurance programmes to reduce transitions into self-rated ill-health. Due to processes of risk-sharing in social protection, it is further reasonable to assume that unemployment insurance is linked to socioeconomic gradients of health at individual level. More specifically, we expect unemployment insurance to mitigate health risks associated with socioeconomic position.

\section{METHODS}

Data

The empirical analyses combine longitudinal panel data on selfrated health from the 2009 release of the European Union Statistics on Income and Living Conditions (EU-SILC) and country-level data on unemployment insurance from the Social Policy Indicator database (SPIN). EU-SILC is an anonymised European social survey, and our analyses are approved by the Committee on Statistical Confidentiality. Selected households remain in the survey for 4 years, before being replaced by another sampled household. Thus, we can here analyse the same individuals in 2006 and 2009. Eurostat expects a response rate of 92\% for the rotating panel, but across the participating countries the share of reinterviewed persons is around $83 \%$. The analysed sample is restricted to respondents aged 18-64 years in 2006 and observed once again in 2009. Fully imputed cases in EU-SILC are excluded. In total we analyse about 48000 valid respondents.

SPIN is an ongoing research infrastructure at Stockholm University providing high-quality comparative data on major social benefit programmes, currently covering 34 countries (for more information, see: http://www.sofi.su.se/spin). The countries in our study are Austria, Belgium, Bulgaria, the Czech Republic, Cyprus, Denmark, Estonia, Finland, France, Greece, Hungary, Ireland, Latvia, Lithuania, Malta, The Netherlands, Norway, Poland, the Slovak Republic, Slovenia, Spain, Sweden and the UK. A few countries in EU-SILC had to be excluded from the analysis. Portugal has a history of inadequate sample sizes in EU-SILC and fails to meet Eurostat's minimum effective sample size for the longitudinal panel. Luxembourg is excluded due to its extremely high level of economic development, which not necessarily reflects the real wealth of residents. Iceland and Italy are dropped because of missing policy data. The Italian unemployment benefit system is very complex, involving several different schemes that vary extensively in terms of coverage and income replacement. SPIN holds no data on Icelandic unemployment benefits.

\section{Measurement}

Our dependent variable is based on the question: 'How is your health in general? Would you say it is...', with five categories of response: 'very bad', 'bad', 'fair', 'good' and 'very good'. Answers ranging from 'very bad' to 'fair' are recoded into an 'ill-health' category. Remaining answers are collapsed into a 'good health' category. In order to analyse transitions into ill-health we compare the dichotomised scores for the same respondent in 2006 and 2009. A change for the worse on our dichotomised measure is coded as 1 , all other instances are coded as 0 . Thus, our focus here is on transitions into self-rated ill-health, disregarding the amount of change in health. For analytical reasons, we separate the incidence and magnitude of change in self-rated health status, not least as social policies may affect the two dimensions differently. The number of transitions into self-rated ill-health ranges between $7 \%$ and $13 \%$ among our countries, and descriptive statistics are in the online supplementary figure A1.

Our core independent variables are the coverage and the net replacement rates of unemployment insurance in 2006. The coverage rate is the number of insured persons according to national insurance registers, measured as a share of the total labour force. The net replacement rate shows the size of benefits after income taxation in proportion of an average production worker's after-tax wage. This replacement rate data is based on model family estimation techniques, where entitlements for stylised households are calculated based on national legislation. ${ }^{24}$ In order to avoid confusion with other types of benefits that people may receive, we have here relied on social rights data for a single-person model family with earnings corresponding to an average production worker's wage, using two periods of benefit duration; a single week and 26 weeks. $^{25}$ Net replacement rates range between 0.14 and 0.93 among our countries, whereas coverage varies between 0.51 and 1. Country details are in the online supplementary figure A2.

\section{Statistical analysis}

Panel data are often subject to first differencing to avoid omitted variable bias. Since we primarily are concerned with policy impacts, this strategy of introducing stationarity is problematic. One reason is that social policies change slowly, and most institutional variation in cross-national time-series data is due to spatial rather than temporal differences. The average changes in coverage and net replacement rates between 2006 and 2009 in our countries are less than -0.02 and -0.01 , respectively. Although reforms to unemployment insurance have been salient in a few countries, for example in the Czech Republic and in Sweden, it is evident that first-differenced regression models analysing short-term changes in coverage and net replacement rates have to deal with problems of time-invariant variables at country level. In this study, we therefore follow an alternative approach and estimate a series of conditional change models.

Conditional change models are common in epidemiology as baseline adjustments of initial health status improves efficiency of results, reduces problems of confounding effects, and avoids bias caused by bounded measurements in health status. ${ }^{26}$ Because individuals are nested within countries, we use hierarchical logistic conditional change models where self-rated health status at first year of observation is included among the explanatory variables, all measured in 2006. Due to non-response in EU-SILC, panel weights are used to increase representativeness of samples to target populations. Panel weights cannot be included in regressions using the common multilevel mixed effects module in Stata/SE V.12.1 statistical package. Instead, we estimate an ordinary logistic regression using the 'logit' command and compute cluster-robust SEs, which are consistent in presence of correlated errors within groups of observations.

\section{RESULTS}

Table 1 shows results from the regression analyses. At individual level, we include the following variables: self-rated health status at first year of observation; age of respondent; self-defined economic status at time of survey (employed as reference category); 
education (tertiary education as reference); female (male as reference); household type (single person as reference). Unfortunately, data on country of birth is unavailable in the 2009 release of EU-SILC panel data. At country level, we include unemployment insurance coverage and net replacement rates as explanatory variables. Since differences in economic development are substantial between the old EU Member States and the Central and Eastern European (CEE) countries, we include GDP per capita (in thousands purchasing power entities) among country-level predictors. To control for overall welfare effort, we use social spending on cash benefits and services as percentage of GDP (excluding expenditures related to old age). GDP and social spending data are from Eurostat. Only explanatory variables of immediate relevance for our hypotheses are shown in the table. Effects of remaining control variables are reported in the online supplementary table S1A.

Model I shows that unemployment insurance is associated with transitions into self-rated ill-health. The coefficient for unemployment insurance coverage is negative and statistically significant. Thus, coverage prevents transitions. The statistically significant positive coefficient of income replacement is unexpected and warrants further analysis. Because the effects of coverage and income replacement may be intertwined, we include a statistical interaction between two variables in model II. SEs of coefficients corresponding to an interaction term and its main effects are often inflated due to multicollinearity, and we therefore test for significance using a model fit. The difference in the BIC (Bayesian Information Criterion) statistic from the baseline model (excluding the interaction term) is well above 10 points, thus showing better fit to the data of the more complex model. ${ }^{27}$ Consequently, the effect of income replacement appears to differ according to the level of unemployment insurance coverage.

Statistical interaction effects between continuous variables are tricky to straightforwardly interpret. Figure 1, therefore, shows predicted probabilities of transitions into self-rated ill-health associated with income replacement at different levels of unemployment insurance coverage. These probabilities are calculated from the predicted log-odds in table 1 above. We show separate predictions for replacement rates varying between 0.2 and 0.8 of an average production worker's net wage. Since statistical precision of our estimates weakens at higher coverage rates, the predicted probabilities calculated at levels close to full coverage should be

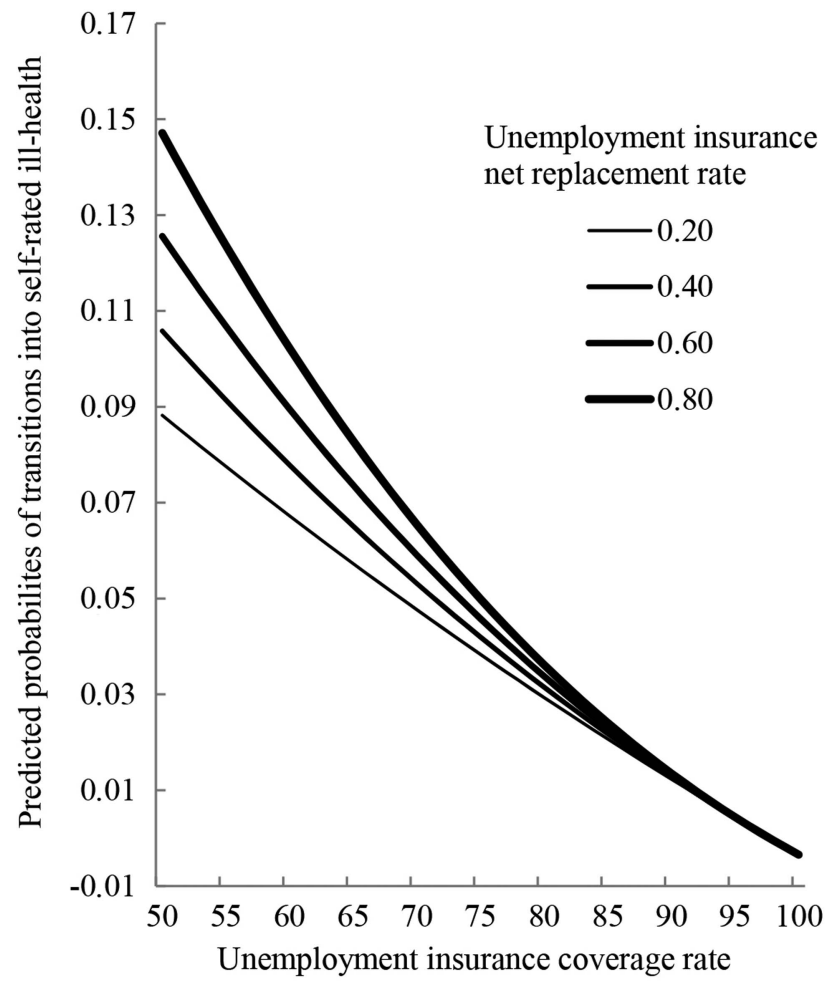

Figure 1 Predicted probabilites of transitions into self-rated ill-health by different levels of unemployment insurance coverage and income replacement in 23 European countries.

interpreted with caution. Nonetheless, it is clear that the effect of income replacement depends on the coverage rate. In fact, the predicted probabilities approach zero (no effect of income replacement) at higher coverage rates. The curvilinear pattern indicates that the interaction effect is stronger in countries combining low coverage and high income replacement.

Our results support the hypothesis that more extensive unemployment insurance programmes reduce transitions into self-rated ill-health at country level. Next, we subject our second hypothesis to empirical test, and investigate whether unemployment insurance also reduces socioeconomic health gradients. In

Table 1 Logistic regression of transitions into self-rated ill-health among respondents 18-64 years in 23 European countries ( $z$ values within parenthesis)

\begin{tabular}{|c|c|c|c|c|}
\hline & Model I & Model II & Model III & Model IV \\
\hline \multicolumn{5}{|l|}{ Individual-level effects } \\
\hline Primary educationt & $0.801^{* *}(0.066)$ & $0.805^{* *}(0.062)$ & $0.940 * *(0.197)$ & $0.798^{* *}(0.069)$ \\
\hline Secondary educationt & $0.558^{* *}(0.053)$ & $0.558^{* *}(0.053)$ & $0.558^{* *}(0.053)$ & $0.344(0.223)$ \\
\hline \multicolumn{5}{|l|}{ Country-level effects } \\
\hline Ui coverage rate & $-1.296^{*}(0.654)$ & $0.042(0.935)$ & $-1.262(0.667)$ & $-1.519 *(0.659)$ \\
\hline Ui replacement rate & $0.523^{* *}(0.168)$ & $2.414^{* *}(0.932)$ & $0.530 * *(0.159)$ & $0.529 * *(0.165)$ \\
\hline Ui coverage rate*Ui replacement rate & & $-2.471(1.348)$ & & \\
\hline \multicolumn{5}{|l|}{ Cross-level effects } \\
\hline Ui coverage rate*Primary education & & & $-0.221(0.274)$ & \\
\hline Ui coverage rate*Secondary education & & & & $0.333(0.301)$ \\
\hline Diff. BIC & & -56.619 & -9.481 & -2.313 \\
\hline
\end{tabular}




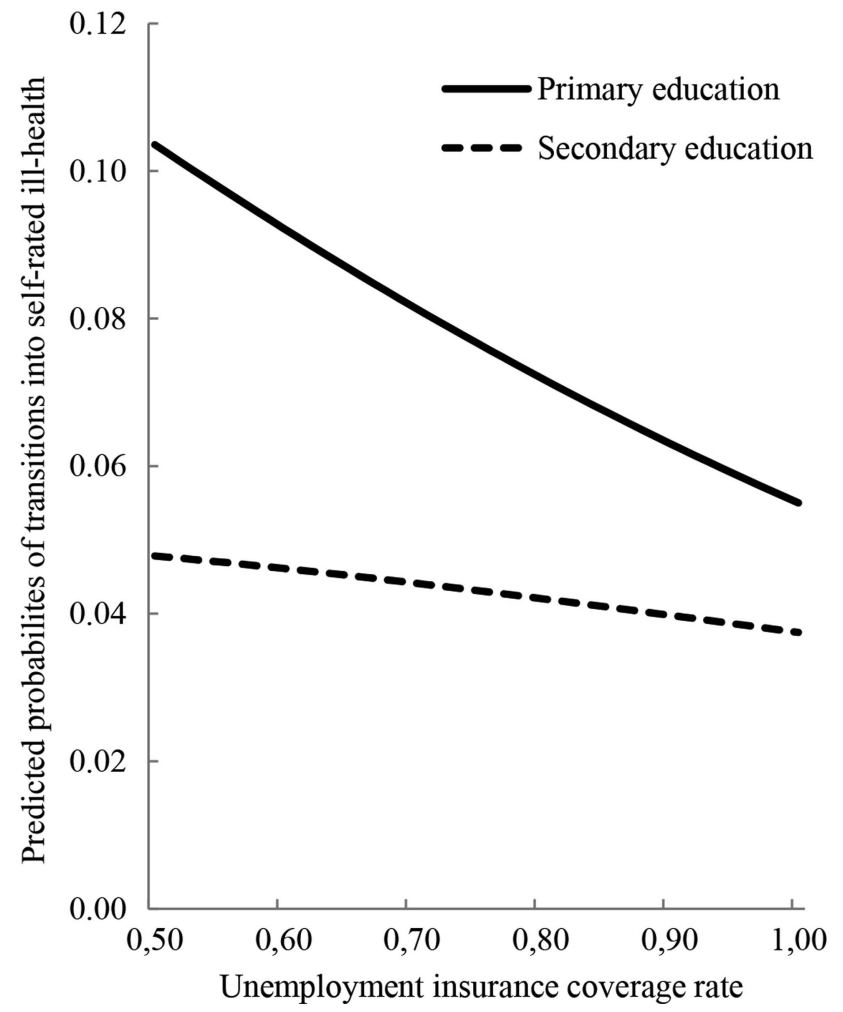

Figure 2 Predicted probabilites of transitions into self-rated ill-health by educational attainment at different levels of unemployment insurance coverage in 23 European countries.

this analysis of cross-level effects, focus is on the interplay between educational attainment at individual level and coverage rates at country level. The individual-level effects in table 1 above indicate that people with primary education are more likely to experience transitions into self-rated ill-health than people with tertiary education. We also find a similar positive association between secondary educational attainment and transitions into ill-health, although effect size is somewhat smaller than for primary education. Here, it should be noted that unemployment status loses its association with self-rated health when education is controlled for, reflecting increased unemployment risks among people with lower education.

As effects of educational attainment may differ across countries due to the structure of unemployment insurance, we include statistical interactions between educational attainment and unemployment insurance coverage. Due to the test of model fit, we include each interaction separately in models III and IV (table 1). According to conventional standards, the BIC tests provide strong (primary education) and moderate (secondary education) empirical support of improved fit of the interaction models, and in order to interpret results, it is again fruitful to calculate predicted probabilities of transitions into self-rated ill-health. Figure 2 shows predicted probabilities of people with primary and secondary education at different levels of unemployment insurance coverage. The adverse health effects of educational attainment evidently level off as coverage increases. The interaction effect is particularly pronounced for primary education, but also appears for individuals with secondary education. Predicted probabilities are nearly halved for people with only primary education when coverage increases from 0.50 to 1.00 , whereas probabilities are reduced by about one-fifth for those with secondary education. Unemployment insurance, therefore, tends to mitigate this particular socioeconomic gradient of health, here measured in terms of health risks associated with educational attainment.

\section{Sensitivity analyses}

We performed additional regressions with a slightly modified dependent variable incorporating the 'fair' response category into the 'good health' category (table 2). This recoding made transitions into self-rated ill-health less frequent, but did not alter the main interpretations of policy impacts (model I). Effects of all control variables are reported in the online supplementary table S2A.

Random effects multilevel models were performed without panel weights using Stata's 'xtlogit' command (model II). These regressions are similar to Dahl and van der Wel's ${ }^{28}$ analysis on inequalities in health. Based on the accuracy of parameter estimates, cluster robust SEs provide a more conservative test of policy impacts.

We also ran regressions where changes in unemployment insurance coverage and income replacement between 2006 and 2009 were included among explanatory variables (models III and IV). No associations between policy change and transitions into self-rated ill-health were found.

Since consequences of the economic crisis differ across regions, we also tested two dummy variables for CEE countries and Southern Europe (model V). None of these regional dummies was statistically significant.

Table 2 Sensitivity analyses: Logistic regression of transitions into self-rated ill-health among respondents 18-64 years in 23 European countries ( $z$ values within parenthesis)

\begin{tabular}{|c|c|c|c|c|c|}
\hline & Model It & Model II‡ & Model III & Model IV & Model V \\
\hline \multicolumn{6}{|l|}{ Country level effects } \\
\hline Ui coverage rate & $-0.753^{*}(0.372)$ & $-0.860 * *(0.147)$ & & $-1.358^{*}(0.670)$ & $-1.397^{* *}(0.436)$ \\
\hline$\Delta$ Ui coverage rate & & & $-1.531(0.833)$ & $-0.984(1.131)$ & \\
\hline Ui replacement rate & $0.474^{*}(0.232)$ & $0.224^{* *}(0.088)$ & & $0.443^{*}(0.228)$ & $0.424(0.246)$ \\
\hline$\Delta$ Ui replacement rate & & & $1.388(1.167)$ & $-0.461(0.747)$ & \\
\hline CEE countries & & & & & $0.664(0.443)$ \\
\hline South countries & & & & & $0.222(0.239)$ \\
\hline \multicolumn{6}{|c|}{$\begin{array}{l}{ }^{*} \mathrm{p}<0.05 ;{ }^{*} \mathrm{*}<0.01 \text {, using cluster robust SEs if not stated otherwise. All regression models include a constant and the full set of control variables, including GDP per capita in } \\
\text { purchasing power adjusted amounts, social spending as percentage of GDP, self-rated health in } 2006 \text {, age, sex, employment status (employed, unemployed, inactive, student) and } \\
\text { family type (single person, lone parent, couple without children and two-parent family with children). } \\
\text { tUsing an alternative coding of self-rated health where the 'fair' response category is included in the 'good health' category. } \\
\text { ¥Random intercept multilevel logistic regression (xtlogit command in Stata) without panel weights. } \\
\text { CEE countries, Central and Eastern European countries; GDP, gross domestic product; South countries, Southern European countries; Ui, unemployment insurance; } \Delta \text {, change between } \\
2006 \text { and } 2009 \text {. }\end{array}$} \\
\hline
\end{tabular}




\section{DISCUSSION}

We have analysed the role of unemployment insurance for transitions into self-rated ill-health among working-age individuals at the onset of financial crisis in 23 European countries. The results show that unemployment insurance coverage reduces transitions into self-rated ill-health, whereas income replacement somewhat surprisingly appears to increase transitions. However, this replacement rate effect approaches zero at higher coverage rates. We also show that coverage rates are related to individuallevel risk factors and socioeconomic gradients of health. Specifically, unemployment insurance coverage reduces the likelihood of people with lower education to experience transitions into self-rated ill-health.

The importance of benefit coverage for a well-functioning unemployment insurance system is intuitively reasonable. Administratively, programme access and eligibility of social risk groups comes prior to determining the size of entitlements. In this regard, income replacement matters less for health when few people are entitled to benefits. It is also evident that unemployment insurance affects the health status of people who are employed. As such, the association between unemployment insurance and self-rated health seems to be closely related to the psychosocial foundations of health. Reviewing social determinants of health, Wilkinson and Marmot ${ }^{29}$ conclude that health is affected before people actually get unemployed, as the first signs of ill-health appear already when people feel their jobs being threatened. Our analyses indicate that unemployment insurance has the potential to counteract this psychosocial mechanism, reducing the social gradient of health linked to educational attainment. Further analyses are welcome to validate our results, not least concerning alternative health outcomes.

Another issue that warrants more attention is regional differences in health and policy impacts. Not only the magnitude of the financial crisis differs across Europe, but also responses to the crisis varied. Although the association between unemployment insurance and transitions into self-rated ill-health is fairly robust in terms of overall regional differences, a few countries introduced major changes to unemployment insurance over the studied period. Such changes may be difficult to analyse in broadly comparative regression frameworks, instead requiring more indepth assessment, for example, through carefully chosen case studies of strategically selected countries, allowing researchers to identify meaningful and testable hypotheses of linkages between policy change and transitions into self-rated ill-health.

The results of our study underscore the merits of a comparative institutional approach in social epidemiology, where welfare states are analysed in terms of programmatic effects, quantifying core dimensions of social rights to facilitate sophisticated statistical analysis of policy impacts relevant for ongoing discussions about public health and other societal outcomes, not least during periods of financial crisis.

\section{What is already known on this subject?}

The prevention of the economic crisis with escalating mass unemployment turning into a health crisis was recently identified as a major challenge by WHO. Comparative research has empirically demonstrated important cross-national variations in health, differences that are assumed to be caused by welfare state organisation. However, we still know little about programme-level effects.

\section{What this study adds?}

This study uses a social rights perspective and empirically shows that unemployment insurance mitigated adverse health effects both at individual and country level during the economic crisis. Especially, programme coverage appears to counteract transitions into self-rated ill-health, and effects are particularly pronounced among individuals with low educational attainment.

Acknowledgements We thank the members of the subgroup Income and Social Protection in the EU FP7 DRIVERS project for providing valuable comments on earlier versions of this study.

Contributors $\mathrm{KN}, \mathrm{OS}$, TF conceived of the study, analysed and interpreted data. $K N, O S$, TF drafted the manuscript and revised it critically for intellectual content. KN, OS, TF gave final approval of the version to be published.

Funding This study has received financial support from the Swedish Research Council (2012-5503), Swedish Research Council for Health, Working life and Welfare (2012-0995) and the European Union's 7th Framework Programme (FP7/2007-2013) under grant agreement number 278350.

\section{Competing interests None.}

Ethics approval Eurostat (Committee on Statistical Confidentiality).

Provenance and peer review Not commissioned; externally peer reviewed.

Open Access This is an Open Access article distributed in accordance with the Creative Commons Attribution Non Commercial (CC BY-NC 3.0) license, which permits others to distribute, remix, adapt, build upon this work non-commercially, and license their derivative works on different terms, provided the original work is properly cited and the use is non-commercial. See: http://creativecommons.org/ licenses/by-nc/3.0/

\section{REFERENCES}

1 Karanikolos M, Mladovsky P, Cylus J, et al. Financial crisis, austerity, and health in Europe. Lancet 2013;381:1323-31.

2 World Health Organization. The financial crisis and global health: report of a high-level consultation. Geneva: WHO, 2009.

3 Marmot M, Bell R. How will the financial crisis affect health? BMJ 2009;338:858-60.

4 Olsen KM, Dahl SA. Health differences between European countries. Soc Sci Med 2007;64:1665-78.

5 Chung $\mathrm{H}$, Muntaner $\mathrm{C}$. Welfare state matters: a typological multilevel analysis of wealthy countries. Health Policy 2007;80:328-39.

6 Eikemo TA, Bambra C, Judged K, et al. Welfare state regimes and differences in self-perceived health in Europe: a multilevel analysis. Soc Sci Med 2008;66:2281-95.

7 Bambra C, Eikemo TA. Welfare state regimes, unemployment and health: a comparative study of the relationship between unemployment and self-reported health in23 European countries. J Epidemiol Community Health 2009;63:92-8.

8 Esping-Andersen G. The three worlds of welfare capitalism. Oxford: Polity Press, 1990.

9 Bolzendahl C. Beyond the big picture: gender influences on disaggregated and domain-specific measures of social spending, 1980-1999. Polit Gend 2011;7:35-70.

10 Goodin RE, Headey B, Muffels R, et al. The real worlds of welfare capitalism. Cambridge: Cambridge University Press, 1999.

11 Kangas 0, Palme J. Social rights, structural needs and social expenditure: a comparative study of 18 OECD countries 1960-2000. In Clasen J, Siegel N, eds. Investigating welfare state change: the 'Dependent Variable Problem' in comparative analysis. Cheltenham: Edward Elgar Publishing, 2007:106-32.

12 Gilbert N. The least generous welfare state? A case of blind empiricism. J Comp Policy Anal 2009;11:355-67.

13 Adema W. Net social expenditure. Labour Market and Social Policy Occasional Papers No. 39. Paris: OECD, 1999.

14 Pega F, Kawachi I, Rasanathan K, et al. Politics, policies and population health: a commentary on Mackenbach, Hu and Looman (2013). Soc Sci Med 2013;93:176-9.

15 Catalano R, Goldman-Mellor S, Saxton K. The health effects of economic decline. Annu Rev Public Health 2011;32:431-50.

16 Granados JAT. Increasing mortality during the expansions of the EU economy, 1900-1996. Int J Epidemiol 2005;34:1194-202.

17 Ruhm CJ. Are Recessions good for your health? Q J Econ 2000;115:617-50. 
18 Shaw M, Dorling D, Smith GD. Poverty, social exclusion, and minorities. In: Marmot M, Wilkinson RG, eds. Social determinants of health. Oxford: Oxford University Press, 2006:211-39.

19 Lynch J, Davey Smith G, Harper S, et al. Is income inequality a determinant of population health? Part 1. A systematic review. Milbank Q 2004;82:5-99.

20 Rodgers GB. Income and inequality as determinants of mortality: an international cross-sectional analysis. Popul Stud 1979;33:343-51.

21 Kawachi I, Kennedy BP. The health of nations: why inequality is harmful for your health. New York: The New Press, 2002.

22 Wilkinson RG. Income distribution and life expectancy. BMJ 1992;304:165-8.

23 Sjöberg 0 . Social insurance as a collective resource: unemployment benefits, job insecurity and subjective well-being in a comparative perspective. Soc Forces 2010;88:1281-304
24 Bradshaw J, Ditch J, Holmes $\mathrm{H}$, et al. Support for children: a comparison of arrangements in fifteen countries. London: HMSO, 1993.

25 Ferrarini T, Nelson K, Korpi W, et al. Social citizenship rights and social insurance replacement rate validity: pitfalls and possibilities. J Eur Public Policy 2013:20:1251-66.

26 Menard S. Handbook of longitudinal research: design, measurement, and analysis. Burlington, MA: Elsevier, 2008.

27 Kass RE, Raftery AE. Bayes factors. J Am Stat Assoc 1995; 90:773-95.

28 Dahl E, van der Wel KA. Educational inequalities in health in European welfare states: a social expenditure approach. Soc Sci Med 2013;81:60-9.

29 Wilkinson R, Marmot M. Social determinants of health. The solid facts. Geneva: World Health Organization, 2003. 